\title{
Long-timed words, Peirce Triangle, Tetrahedron of Ontological Propis
}

\author{
A.N. Pavlenko \\ Institute of Philosophy RAS \\ Russian Federation, 109240, Moscow, Goncharnay, 12/1
}

In this work author analyses names (signs) with the period of existence greater than zero. The whole body of names (signs) is divided into 1) "long-timed words" and 2) "singular words". It is shown that in Peirce Triangle the name (sign) itself, its denotation and meaning may last in different combinations. Typology of "long-timed words" and "singular words" is described. New notion describing the world of possible and real objects is introduced - Ontological Space or Writing Sample (Propis). Tetrahedron of Propis is also introduced with meaning (concept) rather than name (sign) as its apex. It is shown than neither "name" nor "denotate" can exist without sense whilst sense can exist without "name" or "denotate". The fact that Writing Sample (Propis) consists of "segments-streaks" is justified. It is also shown that "long-timed words" do (do not) correspond to these "segments-streaks" of the Propis. Analysis of the Propis led to formulating fourteen axioms that its "segments-streaks" and "long-timed words" obey.

Keywords: ontology, long-timed words, Ontological Writing Sample (Propis), time, space, G.H. von Wright, J. Barwise, model, semantics, logics

\section{Article history:}

The article was submitted on 27.11.2019

The article was accepted on 09.01.2020

For citation: Pavlenko A.N. Long-timed words, Peirce triangle, tetrahedron of ontological Propis. RUDN Journal of Philosophy. 2020; 24 (2): 244-261. DOI: 10.22363/2313-23022020-24-2-244-261

\section{Introduction}

Present work seeks to continue the topic presented in previous publications $[6 ; 10]$. It is suitable to remind that in the named works a new notion describing "ontological space" was introduced — "Ontological Writing Sample (Propis)". I will use it again and this time I am going to call it simply the Propis or mark it as "Xx".

It was also shown before that the Propis encompasses two realities in the aforementioned ontological space: the world of objects possible or not perceived

(C) Pavlenko A.N., 2019

This work is licensed under a Creative Commons Attribution 4.0 International License https://creativecommons.org/licenses/by/4.0/ 
by senses $-\mathrm{S}_{\mathrm{e}}$, and the world of real sense-perceptible objects - $\left(\mathrm{S}_{\mathrm{f}}\right)$, together these two worlds form the full world of the Propis:

$$
\begin{gathered}
\qquad \leftrightarrow \mathrm{S}_{\mathrm{f}} \wedge \mathrm{S}_{\mathrm{e}}, \\
\text { where, }(\mathrm{p} \& \sim \mathrm{p}) \notin \mathrm{S}_{\mathrm{e}} F(\mathrm{p} \& \sim \mathrm{p}) \notin \mathrm{S}_{\mathrm{f}}
\end{gathered}
$$

But describing the Propis's areas we gain nothing in terms of understanding its detailed structure and its structure's properties. Thus, this work is dedicated solely to analyzing these features in depth. In order to do so I will need and introduce several new notions and corresponding terms.

As we remember, Peirce suggested to distinguish three types of objects in order to analyze notions and corresponding terms: signs (names), denotations of these signs (names), and meaning of these signs (names).

It should be noted that while focusing on denotations and meaning of signs Peirce had no interest in the "life-time" of the meaning. I should deem answering this question paramount and in order to do so introduce new concept of "long-timed words".

I should think of such words as "long-timed" that either denote action taken or taking place over some period of time, object existing through some time, or properties and relations having some duration. What do we gain by isolating "longtimed words"?

Firstly, we now can divide all words into two types: "long-timed words" (type-I words) and instant-words (zero-time or "singular") (type-II words).

1) Long-timed words - are "words-segments". Their denotation, the object signified, and their concept or meaning, has life-time or duration greater than an instant (zero-time).

2) Instant-words - are such words that have singularity features (they exist during single "instant" needed to pronounce them).

Any word of natural or artificial language having meaning and denoting certain object might be used as an example of a word-segment. This is rather straightforward and needs no presenting actual example. I will deem as a long-timed word any literally pronounced (written) single word, for example the word "energy", and also a group of words acting as a unity, for example "I promise to buy you a gift" or "metals conduct electricity".

I will think as of instant-words of any word said once by a person in an intense emotional or uncontrollable mental condition and infants" "speech" both having no sense and no denotation or object they refer to. Something like "hey-ho", or "ooola-la", "tinderwinlkes" and such.

I will employ Peirce triangle to analyse long-timed words. 


\section{Peirce triangle}

It has:

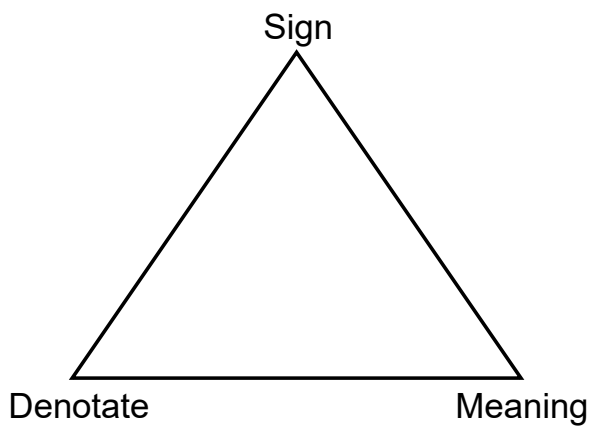

In Peirce triangle sign conveys meaning and denotes object (denotate). Do long-time words has this structure? Doubtless. But more than that, long-timed words (names-signs) have additional component - time. That is exactly why I call them "long-timed". Naturally, the question arises: what exactly bears duration sign, denotation or meaning? That is exactly the question I am striving to answer.

First let's ask: what makes words endure? In other words - what's the basis for their life-time? We think, there are at least three possible answers.

First answer comes as naturally as the question is asked: the sign itself - the term of the language - has a life-time. This is true. But there were peoples - say, Etruscans, that used the name "water" but these peoples have long since vanished and the names they used were gone with them. Thus, I think name-sign cannot be the basis for itself. But then again, one cannot deny the fact that name-signs have the duration in time.

Second answer is that the object (elements class) denoted by the sign has lifetime. In logics terms - the denotate of the name (sign) can endure. Obviously, with the disappearance of the same Etruscans, water as an object, the one we associate today with the chemical compound of hydrogen and oxygen, $\mathrm{H}_{2} \mathrm{O}$, is still present. Therefore, an object can exist before the appearance of the sign-name, during its existence and after its disappearance. In other words, an object designated in human speech by a sign-name can last in time without a sign-name. In this sense, the denotate of some name (sign) ontologically has more solidity than the sign denoting it.

The third answer can be derived from the fact that the meaning of the sign has life-time, that is, that meaning (the totality of the attributes inherent in the object designated by the sign), which is expressed by this sign. I think the situation is the same as with the object (class of elements). Suppose that no objects exist without properties, neither do exist any properties that would not be that of any object. Admittedly, an immediate objection might arise pointing out the possibility to imagine and then introduce such a property as, say, "three-wingedness", but there is no corresponding object to it. I agree, our imagination can come up with the most incredible properties, but here we talk about real objects - (1) either those whose 
existence can be verified empirically (as in the case of "water"), (2) or those whose existence can be admitted through the substantiation of their consistency, which, in turn, can be proved (justified) analytically. For example, the existence of such a controversial object as the "round square" is analytically unacceptable. "Threewingedness" in our real three-dimensional world is not given to us neither empirically (there is no such natural object that would move in space by means of three, rather than two (four) wings), nor analytically — in our three-dimensional world, with the corresponding gravity and environment, the mechanics of flying objects is such that the number of wings must be even, all birds have two wings, some insects (dragonflies) have four wings, etc.

So, we should admit that a property can exist before the appearance of the sign, simultaneously with it and after its disappearance. Indeed, the property of the sky "to be blue" existed even before human learned to pronounce (distinguish) the first signs-names - here the name is "blue". Or to say more - even before the appearance of human.

As I noted above, words (signs, names) are described by the Pierce's triangle. However, developing the topic of "long-timed words", I can add to such characteristics of words as "denotaion" and "meaning" another parameter "time". This turns our triangle into tetrahedron of what I call an "Ontological Writing Sample" or "Ontological Propis".

\section{Tetrahedron of Ontological Propis}

So, having introduced "time" parameter in our discourse of "long-timed" words let's turn to the aforementioned Tetrahedron of Propis (Figure 1).

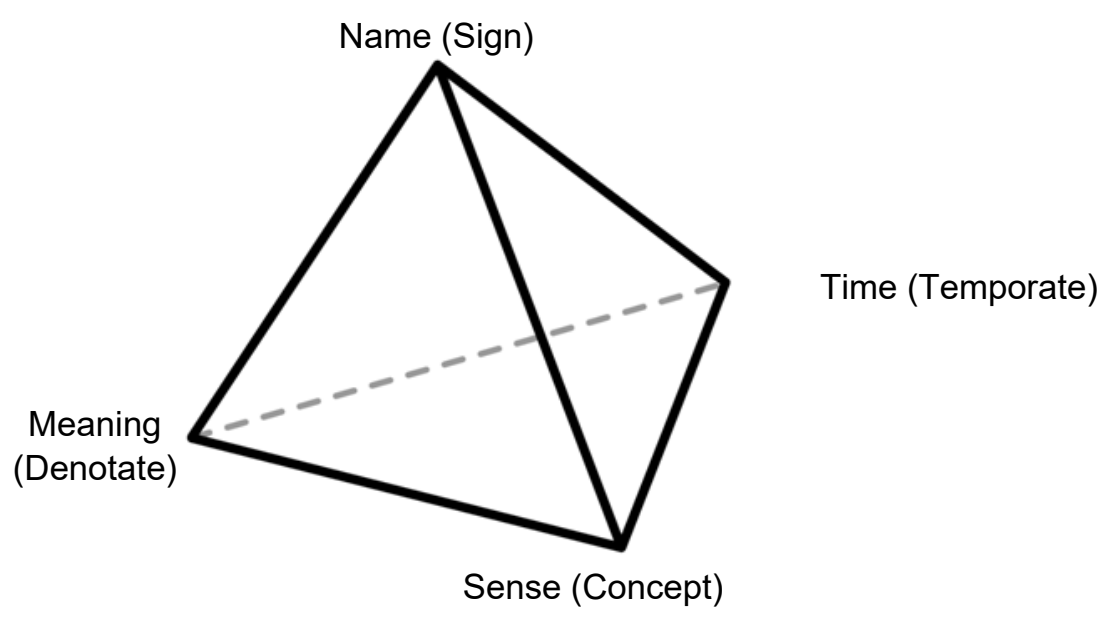

Figure 1

In the Tetrahedron of Propis, the name (sign) denotes the subject, "meaning" conveys the sense (features of the object) and marks the time (lasting in time of the denotation and meaning). If sense is traditionally linked with "concept" and meaning with "denotate", then let's agree to associate time with "temporate". 
Indeed, there is no such sign that does not possess the property of expressing human speech as "duration (lasting)" in time. It only seems obvious and taken for granted, but, in reality, it is very nontrivial. Names (signs) have their own "lifetime" - the duration in time. Not a single sane specialist, whether in logic, in science or philosophy, can object to this. I will give only a few illustrative examples in order to remove all possible objections on the matter.

The first example. The name (concept) "impetus" (from the Latin impetus impulse, impact) was proposed by the French theologian Jean Buridan in the XIV century to explain the movement of a body resulting from a throw (e.g. of a stone) in the air. Buridan believed impetus to be "condensed power", which the thrower transfers to the object (stone) $)^{1}$. Later, the term "impetus" and the idea associated with it were reworked by Galileo Galilei and formed the basis of his "principle of inertial motion". But with the advent of Galileo's theory of motion, the term (concept) "impetus" lost its meaning and ceased to be in demand by science (mechanics). I would say that the life-time of the name (word) ${ }^{2}$ and denotate "impetus" in physics and mechanics ended in the late 16th - early 17 th centuries. In the end, it should be noted that the life of the name (word) of "impetus" was quite long - about three centuries.

Second example. Antique astronomer and mathematician Apollonius of Perga in the 3rd century AD proposed to explain the uneven motion of the planets in the sky with such concepts-names (words) as "epicycle" and "deferent". They existed for a very long time. Even Nicolaus Copernicus still used these concepts in his main work "On the Revolutions of the Heavenly Spheres" [4]. But after the discovery of the three laws of planetary motion by Johannes Kepler in 1609, these names (concepts) lost their power and ceased to be in demand by new European science. In the language of the Tetrahedron of Propis, the life-time of such signs (words) as "epicycle" and "deferent" has ended. But, what is important here - these names (words) had a rather long period of their existence: almost two thousand years. And we cannot subtract this time period from history.

I could continue giving examples from the history of science, recalling such names as "vital force", "cosmic ether", "substance", etc., that have left science and philosophy, but believe above mentioned to be enough.

\section{Typology of names (words) in the tetrahedron of Propis}

If the existence of the tetrahedron of Propis is agreed upon, I now may propose the typology of names built on the following grounds:

1) The meaning. The parameter associated with the presence or absence of meaning allows us to divide all names (words) into meaningful and meaningless:

a) meaningful names (words).

b) meaningless names (words).

\footnotetext{
${ }^{1}$ For more on the topic see [2. P. 272-275].

${ }^{2}$ When I say that the lifetime of the name "impetus" is over, I mean that it is discontinued in mechanics (in physics), preserved only in reference books and historical and scientific research.
} 
2) Denotation. The parameter associated with the presence or absence of denotation allows for dividing all names (words) into those that have denotation and those that do not:

c) names (words) that have denotation.

d) names (words) that do not have denotation.

3) Life time. The parameter associated with the presence or absence of lasting in time allows for dividing all names into long-timed and instant:

e) long-timed names (words).

f) instant names (words) (singular names).

Such a typology makes it possible to analyse the relationship of each type of name with other types. In other words, it is interesting to consider how the names of type 1,2 and 3 relate?

a) Consider cases 2 and 3

$$
\begin{aligned}
& c-e \\
& d-f
\end{aligned}
$$

We have four combinations

$$
\begin{aligned}
& (\mathrm{c}-\mathrm{e}) \&(\mathrm{c}-\mathrm{f}) \\
& (\mathrm{d}-\mathrm{e}) \&(\mathrm{~d}-\mathrm{f})
\end{aligned}
$$

I. (c-e) names that have denotation and long-timed exist II. $(\mathrm{c}-\mathrm{f}) \quad$ names that have denotation and instant names do not exist III. (d - e) names that do not have denotation and long-timed exist IV. (d - f) names that do not have denotation and instant names exist

乃) Consider cases 1 and 2

$$
\begin{aligned}
& (\mathrm{a}-\mathrm{c}) \&(\mathrm{a}-\mathrm{d}) \\
& (\mathrm{b}-\mathrm{c}) \&(\mathrm{~b}-\mathrm{d})
\end{aligned}
$$

V. $(\mathrm{a}-\mathrm{c})$ names that have meaning and denotation exist

VI. $(\mathrm{a}-\mathrm{d})$ names that have meaning but do not have denotation exist

VII. $(b-c)$ names that do not have meaning but have denotation ${ }^{3}$ do not exist VIII. $(b-d)$ names that do not have meaning and do not have do not exist denotation

$\gamma$ ) Consider cases 1 and 3

$$
\begin{aligned}
& (a-e) \&(a-f) \\
& (b-e) \&(b-f)
\end{aligned}
$$

\footnotetext{
${ }^{3}$ In this case, we consider those and only those names (words) that already exist or existed in the past. We cannot consider names that, for example, are already in the Propis, but which will be proposed by man, for example, only after two centuries. Currently, they are simply not given to us.
} 
IX. $(\mathrm{a}-\mathrm{e}) \quad$ names that have meaning and long-timed

exist

$\mathrm{X} .(\mathrm{a}-\mathrm{f}) \quad$ names that have meaning and instant names

do not exist

XI. $(b-e)$

XII. $(b-f)$

names that do not have meaning and long-timed

do not exist

It is easy to see that there may be situations when the concept's life-time can last even when the denotate's life-time has ended. For example, the concept of the name "USSR" continues to exist, while the denotate of this name ceased to exist in 1991.

Question: what does the temporal logic say? It speaks of statements that at some point in time can be either true or false, without distinguishing what lasts and what doesn't. I believe that temporal logic should encounter difficulty if it considers, for example, "long-timed words" that have meaning in the present (and have sense) and have meaning in the future (but not having sense then) in the Prior modes - $G p$.

\section{"It will always be that $p "[7 ; 11]$}

An example is very easy to come up with - archaeologists often find "artefacts" that have denotation (literally, denotate - the objects themselves in their material form), but their meaning is not clear to modern man.

In other words: the time may come when $p$ will not have neither meaning nor denotation, as was shown in the two above examples.

So, if we consider the names with their "denotation", "meaning" and "lifetime", we get eight combinations $\left(2^{3}\right)$ with two values "yes" and "no" and three components - "Meaning", "Denotation", "life-Time":

1) Having denotation, having meaning, having life-time

2) Not having denotation, having meaning, having life-time

$(\mathrm{d}, \mathrm{m}, \mathrm{t})$

3) Having denotation, not having meaning, having life-time $(\neg \mathrm{d}, \mathrm{m}, \mathrm{t})$

$(\mathrm{d}, \neg \mathrm{m}, \mathrm{t})$

4) Having denotation, having meaning, not having life-time

$(\mathrm{d}, \mathrm{m}, \neg \mathrm{t})$

5) Not having denotation, not having meaning, having life-time

$(\neg \mathrm{d}, \neg \mathrm{m}, \mathrm{t})$

6) Having denotation, not having meaning, not having life-time

$(\mathrm{d}, \neg \mathrm{m}, \neg \mathrm{t})$

7) Not having denotation, having meaning, not having life-time $\quad(\neg \mathrm{d}, \mathrm{m}, \neg \mathrm{t})$

8) Not having denotation, not having meaning, not having life-time $(\neg \mathrm{d}, \neg \mathrm{m}, \neg \mathrm{t})$

Now let's try to change the angle we look at the problem. To do so, I will use the aforementioned Tetrahedron of Propis. Obviously, it was a pyramid with anthropocentrism as its apex, where names and meanings are firmly connected with a man. This position can be expressed figuratively like this: "If there is a person there are names, if there is no person - there are no names!" Otherwise, proponents of anthropocentrism may reasonably ask: "And who gives these names?"4

\footnotetext{
${ }^{4}$ Here I will leave aside the position of Plato and the polemic around it, set forth in the "Kratil" dialogue, according to which the world calls itself and means itself.
} 
Now we will change the semantic accents of the tetrahedron of Propis so that "meaning" will take place at the apex of the pyramid instead of the "name" (word). The basis for such a move is the following state of affairs: meaning [as a characteristic (attribute or property) of an object] can exist without a name and denotate, but neither denotate nor a name can exist without one or another meaning. By "meaning" we mean the essential features of an object, both imaginary (possible) and real, that is, given in sensory perception.

Let us also agree that the so-called "meaningless names (words)" still have some meaning, even if in a negative sense. After all, the "absence of meaning" is itself meaningful. So, for example, such an important concept in explaining the nature of information as "data", given in the Stanford encyclopaedia, is defined through the denial of a property (attribute): "Basic datum" is an assumed fact regarding some difference or lack of uniformity (italics mine - AP) in any

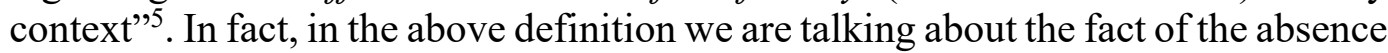
of the property of "uniformity". Having understood this, we will now depict the semantic pyramid, with "meaning" at the top (Figure 2):

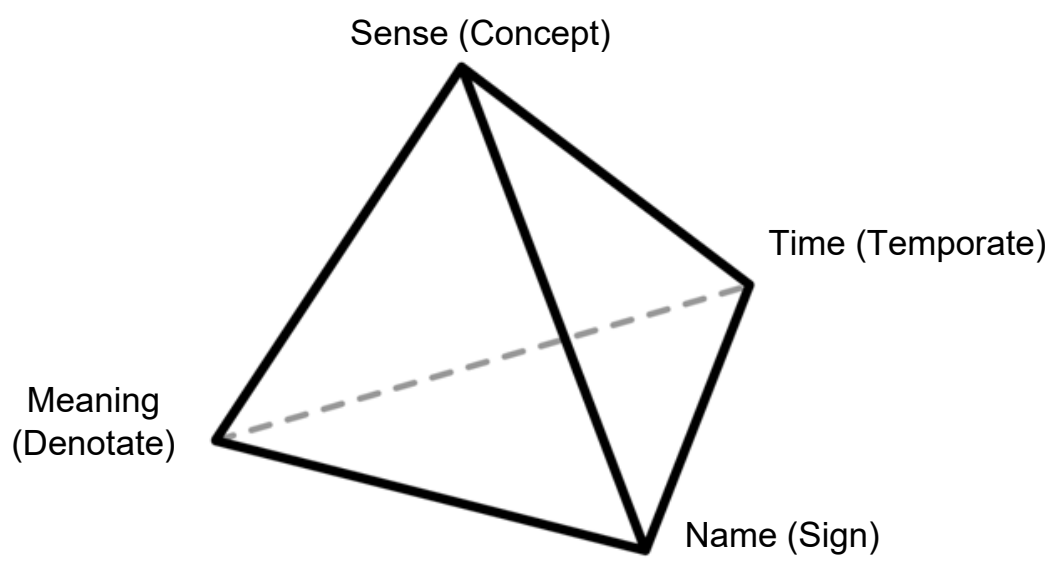

Figure 2

What it brings us?

1) It brings a certain stability to the world. Nothing contradictory (meaningless) can penetrate into this "meaningful world". To a certain extent, this is "consistency in itself".

2) This is not a world of anthropocentrism and anthropolatry. The man who gives names to objects is no longer at the top of the tetrahedron.

3) The sense is more fundamental than the "name" (anthropolatry) and the "denotate" (positivism), since the denotate (object) is only the realization of the sense that always precedes it (the object). The name is all the more secondary.

In the tetrahedron in Fig. 2, it turns out that the sense has (does not have) its own meaning, has (does not have) its name-sign (word), has (does not have) the duration of its existence.

\footnotetext{
${ }^{5}$ URL: https://plato.stanford.edu/entries/information/
} 


\section{The space of "time"}

Based on the typology I proposed earlier, one can say that this is the situation with "long-timed words", from the point of view of the Tetrahedron of Propis. In other words, the world was looked at as the "Time of Space". This approach is associated with the study of the von Wright concept [1] in a previous work [6;10]. In other words, I considered events (objects) in the world as events (objects), "immersed" in "time", the main property of which is the duration of events and objects of the world.

Now let's shift the angle of the problem and consider the same world - the world of the "ontological space" — but, from a different point of view: the point of view of the "space of temporal changes", referred to in the above work as "Space of Time" (SoT). What do we see then? We see the same world, but with completely different properties.

All that in the ToS world was a sequence of time-related events (basically "points" on the time line, for which one can apply characteristics such as "past", "present" and "future" or "earlier" - "later"), in the world of SoT turns out to be a "streak" or "a special lasting line ("segment")" with respect to which there is inside itself — no "earlier" or "later". The space of time is, figuratively speaking, a "frozen crystal of the time-bearing states of the world", considered immediately and in its entirety. There is neither "present", nor "past", nor "future" in it. More precisely - the "past", "present" and "future" exist in it, but only as a purely human convention that helps to order the world in human ideas.

In such a world, the "past", "present" and "future" are given at once and in full. I call this world the Propis ("Ontological Propis"). I want to pay specific attention to the fact that I'm not the first doing this.

For the first time, a purely scientific description of such a world became possible after the wave function of the universe was proposed by J. Wheeler:

$$
\Psi=\frac{\left(d z_{x y}, \phi\right)}{d t}=0,
$$

where $d z_{x y}$ is space metrics, $\phi$ - matter fields, $d t$ - time.

Its peculiarity lies in the fact that the Universe as a whole "in itself" does not depend on time, therefore the equation equals zero ${ }^{6}$. This means that the Universe within itself does not undergo any changes. It is observer who introduces evolution into it (changes in the time of physical processes), reducing the total wave function of the Universe to that part of it that he observes.

Naturally, the question arises: is it possible to conduct not physicalmathematical analysis, but philosophical (logical) one of the states of the world (events and their connection) in such world, which is ontologically expressed as Propis, if time is not given ontologically in this world? Yes, I think it is.

\footnotetext{
${ }^{6}$ See paper [5] for more.
} 
A minimal analysis of such Propis, if the apparatus of temporal logic using temporal relations between statements (in the case of the model of Prior [11] and his followers [3;8] left aside, can be represented as relation of order. But the temporal model of G. von Wright, in which not "statements" (as in Prior's work) are analysed, but "events" [1] and J. Barweis's model with respect to the description of "situations" and "state of affairs" [9], turn out to be much closer to the description of such world, as I see it.

It should be specifically noted that the relation of order - the serial nature of something - is also inherent to time. However, regardless of time, the relation of order - a fixed position and arrangement of world states (objects) - is also inherent to space. In this case, we will consider the concept of space not in the physical, but in the broadest sense - as the "space" of such an abstract object, which I call the "Ontological Propis".

To describe the relation of order in the Propis I will introduce special terms and characters:

\section{Primary:}

1) a, b, c, d ... - states of the world (events) of the world. Objects in the broadest sense.

The states of the world are understood in the proposed model as "time segments", which I will designate with the Cyrillic " $\mathbf{}$ ", and which, considered from the point of view of SoT, already appear as "extended segments". After all, now I consider not the changing states of the world in time, but the space of such changes. Therefore, by "duration of the time segment" in the Propis I simply mean "the length of the considered segment".

Further, let's assume that the entire Propis consists of "extended segments", the role of which, from a semiotic point of view, is played by names (words), and from the ontological one, either by their denotates, or their concepts, or various combinations of those. Then let's assume that all segments of the Propis have duration (length) equal $n$. Segments that are of a singular nature (the length of which equals zero) will be considered simply as segments with an infinitely small length. This is entirely acceptable, since Galileo already considered "peace" as "infinitely slow movement."

The segments can be arranged in relation to each other in any of the listed orders: "be behind (after)", "be in front of (before)", "be near". Since all the segments for the "imaginary super-observer" are given at once and in full (so far only by analogy - our consciousness with its ways prevent us from perceiving otherwise) I can say that in the Propis there is universal "simultaneity" (I specifically emphasize its anthropomorphic and quasi-spatial character, because in the Propis there is no time in its human understanding), that is, the factual snapshot on which the entire Propis is captured. In this case, by "simultaneity" of the Propis I mean the invariable "picture of Propis". It could be said that the "time" is revealed to the super-observer in one and only way - he sees it as an eternity, that is, precisely as a "picture" formed by segments and their mutual arrangement, 
inside of which anthropovisualized changes in time have occurred. Each of these segments has a beginning in time and has an end.

Therefore, in the proposed approach, time within segments is by no means denied, but only the limitations of such a temporal description of the world are shown, which I have demonstrated to a large extent earlier [6;10]. I have already shown that the model proposed by von Wright rests on the impossibility of explaining a world in which there is no change. In fact, where the description of the world in time ends, its description in space begins. Space, in fact, turns out to be a more universal attribute of the world than time. Let's introduce additional terms for describing such a world:

2) Operators:

$\Delta$ — "to be after" ("beyond" the border of any segment)"

$\Theta$ - "to be before" ("in front" the border of any segment)"

$\Xi$ - to be near ("in the vicinity")

\section{Secondary:}

3) Logical symbols: $\&, \vee, \supset, \leftrightarrow$, needed to discuss the properties of the Propis in a special language that can describe the characteristics of the Propis - the language of statements.

4) Next, following remark has to be made: speaking of the Propis, I will consider the "segments" of the Propis and the "streaks" of the Propis as synonymous concepts.

\section{Features and properties of the Propis, expressed in axioms}

Now let's introduce the essential features and properties of such a Propis, fixed in axioms:

Axiom I. The world is an ontological Propis (Propis). Let's designate the Propis with the symbol "XX".

Axiom II. All events in the world are segments-streaks (hereinafter indicated by the Cyrillic " $\$$ ").

Axiom III. The segments-streaks form lines (contours) (hereinafter indicated by Cyrillic " $\boldsymbol{\Lambda}$ "). Propis lines are the sequence of segments arranged in the Propis in one way or another. The Propis lines are formed by the spatial position and various relations between the segments-streaks.

Axiom IV. The segments-streaks are integral and indivisible.

Axiom $V$. The segments-streaks are interrelated in some respects. Let's call these relations - "relations of order" - $\mathrm{R}_{п}$. I denote the types of such relations by the operators introduced above $(\Delta ; \Theta ; \Xi)$.

Axiom VI. Axiom of direct relation of order:

"If segment $b$ is after segment $a$, then segment $a$ is not after segment $b$ ".

In the formal logical expression: 


$$
(b \Delta a) \supset \sim(a \Delta b)
$$

Axiom VII. Axiom of the inverse relation of order:

"If segment $a$ is in front of segment $b$, then segment $b$ is not in front of segment $a$ ".

In formal expression:

$$
(a \Theta b) \supset \sim(b \Theta a)
$$

Axiom VIII. Axiom of direct transitivity of relation of order:

"If segment $b$ is after segment $a$, and segment $c$ is after segment $b$, then segment $c$ is after segment $a$ ".

$$
(b \Delta a) \&(c \Delta b) \supset(c \Delta a)
$$

Axiom IX. Inverse transitivity of relation of order:

"If segment $a$ is before segment $b$ and segment $b$ is before segment $c$, then segment $a$ is before segment $c$.

$$
(a \Theta b) \&(b \Theta c) \supset(a \Theta c)
$$

Axiom X. Symmetry of relation of order. If segment $a$ is near segment $b$, then segment $b$ is near segment $a$.

$$
(a \Xi b) \supset(b \Xi a)
$$

From this follows that:

$$
\begin{aligned}
& \sim(a \Xi b) \supset \sim(b \Xi a) \\
& \sim(b \Xi a) \supset \sim(a \Xi b)
\end{aligned}
$$

Axiom XI. Reflexivity of relation of order between segments.

If $\left(a \leftrightarrow a^{\prime}\right)$, then $\left(a^{\prime} \leftrightarrow a\right)$,

Axiom XII. The Propis is the sum of the conjunctions of the totality of its "segments-streaks" "จ":

$$
\not \mathscr{X}=\sum\left(\nabla_{1} \& \nabla_{2} \& \ldots \& \nabla_{n_{i-1}} \& \theta_{n_{i}}\right),
$$

where $n_{i}$ - stands for the number of segments-streaks from the first one to the full total.

Axiom XIII. Consistency of relation of order. The Propis is a set of consistent (possible ${ }^{7}$ ) and only consistent (possible) segments-streaks (events). Let us mark possible (consistent) segments-streaks as " $\mathbf{B}\left(\boldsymbol{\nabla} \mathrm{n}_{\mathrm{i}}\right)$ ". Accordingly, impossible (contradictory) segments - features will be denoted as “ $\sim \mathbf{B}\left(\boldsymbol{\theta}_{\mathrm{j}}\right)$ ". As a result, we

\footnotetext{
${ }^{7}$ In this case, we consider the "possibility" in the most general (qualitative) form and do not use the formal operator of possibility " $\nabla$ ". A description of the ontological space with the "opportunity" operator will be given later in another paper.
} 
final definition of the Propis: The Propis is the difference between the world of possible (consistent) and the quasi-world of impossible (contradictory) segmentsstreaks:

$$
\not{X}=\boldsymbol{B}\left(\boldsymbol{\phi} n_{i}\right)-\sim \boldsymbol{B}\left(\boldsymbol{\phi} n_{j}\right)
$$

Further, the language $L o$ might be introduced to provide the framework for description of segments-streaks $\boldsymbol{O h}_{i}$ and the relations between them. Then $\mathbf{O n}_{i}$ segments will be equivalents of the corresponding statements in the framework of the proposed language. So, if the statement $\boldsymbol{p}$ belongs to the language $L o(\boldsymbol{p} \in L O)$, and $\mathrm{O}_{i}$ is the corresponding line-streak, then

$$
L_{O}(\boldsymbol{p})=\left\{\boldsymbol{O}_{\mathrm{n}_{i}}\right\} .
$$

Accordingly, the line (contour) of the Propis ( $\boldsymbol{\Lambda})$ will be equal to the sum of the conjunctions of its constituent segments-streaks:

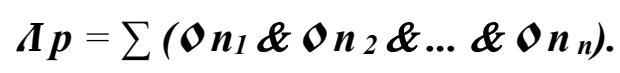

In this case, it turns out that the totality of human statements about the segments will be equal to the sum of the segments themselves:

$$
\sum\left(L p_{1} \& L p_{2} \& \ldots \& L p_{n}\right)=\sum\left(\circlearrowleft n_{1} \& \circlearrowleft n_{2} \& \ldots \& \circlearrowleft n_{n}\right) \text {. }
$$

In fact, this equality suggests that the linguistic equivalent of "segmentsstreaks" of the Propis is what I call "long-time words" (names), place of these can be taken by single names or simple (atomic) statements.

But, after all, there are immeasurably more segments-streaks than statements about them. It seems that the most natural solution would be to limit the number of statements about segments-streaks to the amount that was given to human in the past and given in the present. Accordingly, human is open to the number of segments about which he or she can speak.

Now let's take the possible (consistent) segments-streaks — the " $\boldsymbol{E}\left(\boldsymbol{O} n_{i}\right)$ " and select from them those that are given to human. Let us denote them with Cyrillic " $A$ ". In this case, it turns out that:

Axiom XIV. The Propis opens to human in the form of only the given segment-streaks:

$$
\not{X}=\left(\left(\boldsymbol{B}\left(\boldsymbol{O} \mathrm{n}_{i}\right) \&, \boldsymbol{A}\left(\boldsymbol{O} \mathrm{n}_{i}\right)\right)\right.
$$

Thus, the segments-streaks given to a person include those and only those segments-streaks that are open to him in the form of statements about possible consistent segments- streaks. It can be shown in the following figure 3 . 


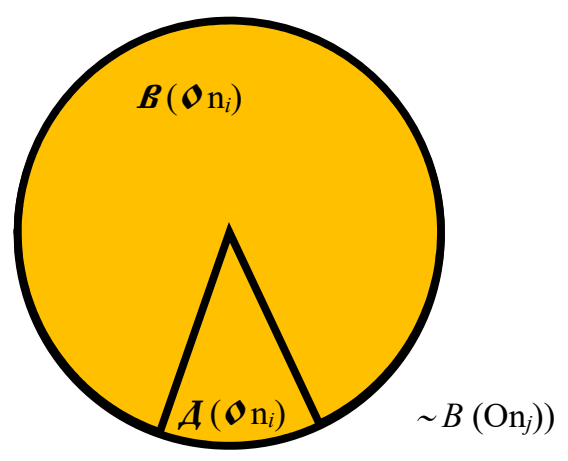

Figure 3

Now let's build the simplest model of the Propis, based on "long-timed words". In the long-timed words, let us take such a property that was proposed above and was called "temporate" of the concept and denotate.

So, for example, the temporate of the concept "phlogiston" has existed from the time of Philoponos (5-6th centuries AD) to the present day, and the temporate of the denotate "phlogiston" was completed (banned) in the second half of the 19 th century.

The temporate of the concept of "space ether" has existed since antiquity to the present day, and the temporate of the denotate of "space ether" was completed (banned) at the beginning of the 20th century with the advent of the MichelsonMorley experiment (1904). These examples can be continued further: "natural place", “equants", “deferents", etc.

This assumption is easily justified as follows: one can easily demonstrate that the "meaning of the name" exists (as an "idea", as a "thought")

1) before denotate, with denotate, after denotate.

2) before the name, with the name, after the name.

However: i) denotate, cannot exist without meaning, but can exist without a name.

ii) a name cannot exist without meaning, but it can without denotate.

Names that are designation of meaninglessness (for example, "abracadabra") themselves cannot be meaningless, as they indicate the meaning of "meaninglessness". Meaning, figuratively speaking, cannot be meaningless.

It follows that the truth can be established both in relation to "meaning" and in relation to "denotate", but not to "name".

In relation to denotate - verification or falsification.

In relation to meaning - consistency, proof, justification.

Truth is not limited to an attitude, although includes it, but ultimately it is the state of the Propis - "clearness".

For example, deductive proof is not an establishment of the relationship between something and something. 
The concept of "attitude", I think, was promoted by empiricists who constantly impose on us a comparison of our ideas with reality ${ }^{8}$.

And this epistemological empiricism was initiated by Aristotle with his correspondent definition of truth:

"... to speak of the existing, that it does not exist, or of the non-existent, that it does, is to speak false; but to say that existing exists is and non-existing does not, means to speak truly" (Met.1011b25).

In his definition, Aristotle does not specify what is being discussed: material or ideal existence. And is it the same thing to talk about the existing, for example, as a "cup", or about the existing, as a "number" or "cosmos"? And therefor can Plato's "idea" be true?

In fact, the truth in the Propis is its picture.

If we understand the truth as the relation of the "sign" to the "signified", then we are talking about the truth as a relation. If we understand the truth as a "state of affairs", as a "world", then the relation will be inappropriate, unless we consider the "world in itself" as auto-reflexivity, that is, as "auto-attitude". Then the selfequality of the world will also be a relation. Continuing this idea, it is fair to say that "the truth of the Propis is simply its self-equality":

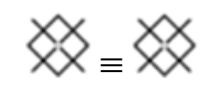

Somewhat more strictly: the Propis cannot be neither true nor false (if truth is understood as the "relation" of knowledge to the knowable), it can only be. Plato said that ideas cannot be "true or false," they can only be, and therefore always true exactly as ideas themselves. Same applies to the segments of Propis. My "New Critical Realism" follows the same line of thinking. If the theoretical position is proved, then it is proved for all possible worlds in which the conditions under which it is proved are satisfied (that is, with any substitution of the value of a variable).

Consistent and proven universally valid statements are always true, regardless of whether they are empirically confirmed or not.

After all that has been said, let's introduce the concept of the "size" of a segment. By "size" I mean the length of the segment, expressed by the "length of its life-time".

As the simplest unit of "size", let's take the "life time" of the long-timed word, regardless of its temporal extent.

For example, the distance between Galileo's formulation of the principle of inertial motion and the present is 4 centuries.

Next, let's equalize ontologically the "length" of the segments. Then it turns out that many of them can exist near each other and many — cannot. The topology of the Propis appears.

The main thing that should be noted is that the usual implication does not work in the Propis, since the present does not follow from the past, and the future from

\footnotetext{
${ }^{8}$ I showed the insurmountable difficulties of "empiricism" in the book [10].
} 
the present. But then what? I think that there is a sequence, but there is no dependence in the Propis. Being naive, as D. Hume thought (he said "by force of habit"), we mistake sequence for dependence. "After that" does not mean "because of that."

When we talk about logical following, we are essentially talking about sequential following in our thinking. Our thinking and consciousness look at the world trough conceptual network that facilitates our perception of the world by creating logical dependencies found in logical concepts, judgments and conclusions. What seems sequential to us is simply an already existing sequence of segments-streaks of this world. Our consciousness, like a cursor, moves "along" the Propis, leaving sections of the Popis in the "past". But there is no past in the Propis, just as there is no present and future. We humanize the Propis. Our consciousness misleads us.

The implication is applicable to our names - long-timed words. Between long-timed words, a conditional connection is really possible. In other words, the implication is applicable to the human analogue of the Propis, but not to the Propis itself. We say that "if it rains," then "the roofs of the houses are wet." And if it doesn't rain, can the roofs be wet? And if the roofs are wet — does this mean that it has rained? We see that between the "wet surface of the roofs" and the "fact of rain" there is an ontological gap. We believe that, usually, when it rains, then, usually, the roofs of the houses are wet. We also believe that usually "if the Sun rises in the East, then it sets in the West." But it can explode at any given moment after sunrise or sunset swallowing the Earth and, having dumped a significant part of the substance, turn into a white dwarf, and then our "usual" rule, our habit, will fail again.

After all, if the implication was universal, then we could predict any fact of the future. That was Laplace's dream. Then the future (events and processes in the future) would be reduced to an ordinary logical and mathematical calculation. Of course, we can make forecasts, but they are accurate only with a certain degree of probability. "Why?" one can ask. Because we do not have all the information about the topological state of the whole Propis. We can generalize only that small part of our own "vicinity" $(\Xi)$, which is given to us by Д $(\Xi)$, but nothing more. Moreover, this vicinity is both sensual (experimental) and mental (theoretical) in nature. We are able to see empirically that and only that which is open to us theoretically. It will be appropriate here to recall the thesis of Duhem-Quine: all empirical facts are theoretically loaded. That is given to us theoretically is also limited.

Such a description of the long-timed words - segments is consistent with the description of T. Kuhn's paradigms, which can exist one after the other, one before the other and one near the other, but whose languages, as Kuhn thought, are not comparable. In general terms, the idea of "long-timed words" was correctly guessed by him, with the only difference being that the "conceptual core of the paradigm" was his "long-timed word". 


\section{Conclusion (Back to "long-timed words")}

Now, after understanding the meaning of the Propis and its connection with the SoT model, let's return to the "long-timed words" discussed at the beginning of the article. It is easy to guess that the "long-timed words" are the names of the "lasting segments" of the Propis. Let us mark the "long-timed words" with Cyrillic "G", and "segments-streaks" of the Propis with Cyrillic " $\mathbf{}$ ".

As we have already noted in the axioms, expressions of the language are put in correspondence with the segments-streaks of the Propis.

$$
\sum\left(L \boldsymbol{p}_{1} \& L \boldsymbol{p}_{2} \& \ldots \& L \boldsymbol{p}_{n}\right)=\sum\left(\boldsymbol{\vartheta}_{1} \& \boldsymbol{\vartheta}_{n_{2}} \& \ldots \& \boldsymbol{\vartheta}_{n}\right) .
$$

Now, instead of the Latin designation of language expressions on the left side, we will use the Cyrillic designation of the long-timed words "E" and get the following complete expression, reflecting the essence of the Propis:

$$
\sum\left(\boldsymbol{F} \boldsymbol{p}_{1} \& \boldsymbol{\sigma p}_{2} \& \ldots \& \boldsymbol{\theta} \boldsymbol{p}_{n}\right)=\sum\left(\boldsymbol{O}_{1} \& \boldsymbol{o}_{2} \& \ldots \& \boldsymbol{o}_{n}\right) .
$$

This means that for the "super-observer" there is a corresponding long-timed word for each segment of Propis.

\section{References}

[1] Wright GH von. Logiko-philosophskie issledovanija. Izbrannie trudi. Moscow: Progress; 1986. (In Russian).

[2] Gaidenko VP, Smirnov GA. Zapadnoevropeiskaja nauka v srednie veka. Obschie principi i uchenie o dvizhenii. Moscow: Nauka; 1989. (In Russian).

[3] Karavaev EF. Vrenmennaja logika. Symbolicheskaja logika. Ch. XII. St. Petersburg; 2015. P.415-451. (In Russian).

[4] Copernicus N. Ob obraschenijach nebesyich spher. Moscow: Nauka; 1964. (In Russian).

[5] Linde AD. Physika elementarnich chastic I inflationnaja cosmologija. Moscow: Nauka; 1990. (In Russian).

[6] Pavlenko AN. «Prostranstvo vremeni» (SoT) ili «vremja prostranstva» (ToS): kommentarij na model vremeni G. von Wrighta. RUDN Journal of Philosophy. 2017; 21 (2):179-191. (In Russian).

[7] Prior AN. Vrenmennaja logika I neprerivnost vremeni. In: Semantika modalnich I intesionalnich logic. Moscow: Progress, 1981:76-97. (In Russian).

[8] Symvolicheskaja logika. St. Petersburg; 2015. 505 p. (In Russian).

[9] Barwise J. Situation in logic: SCLI Lecture notes. No.17. Stanford: Leland Stanford Junior Univ.; 1989. $321 \mathrm{p}$.

[10] Pavlenko Andrey. How can G.H. von Wright's model of Time generate two logical squares? (The opposition "Time of Space" (TOS) and "Space of Time" (SOT)). In: Theoria vs Observatio: vozvtaschenie iz obmoroka. St. Petersburg: Aletheia;2018. P. 279-291.

[11] Prior AN. Time and modality. Oxford; 1957.

\section{About the author:}

Pavlenko A.N. — Doctor of Philosophy, Professor, leading researcher at the Institute of philosophy of the Russian Academy of Sciences (e-mail: anpavlenko@mail.ru). 


\title{
«Длящиеся слова», треугольник Пирса и тетраэдр онтологической Прописи
}

\author{
А.Н. Павленко \\ Институт философии РАН, \\ ул. Гончарная, 12, Москва, Россия, 109240
}

Предметом анализа настоящей работы являются имена (знаки), имеющие время существования больше нуля. Введено разделение всех имен (знаков) на 1) «длящиеся слова» и 2) «слова сингулярные». Показано, что в треугольнике Пирса могут длится в разной комбинации имя (знак), его значение и его смысл. Построена классификация «длящихся слов» и «сингулярных слов». Введено новое понятие, описывающее мир возможных и реальных объектов - онтологическое пространство (Пропись). Введен тетраэдр Прописи, вершиной которого является не имя (знак), а смысл (концепт). Показано, что ни «имя», ни «денотат» не могут существовать без смысла, а смыл может существовать без «имени» и без «денотата». Обосновано, что Пропись состоит из «отрезков-черт». Показано также, что длящиеся слова имеют (не имеют) соответствие с этими «отрезкамичертами» Прописи. Анализ Прописи позволил выявить четырнадцать аксиом, которым подчиняются её отрезки-черты и длящиеся слова.

Ключевые слова: «длящиеся слова», онтологическая пропись, время, пространство, Г. фон Вригт, Дж. Барвайс, модель, семантика, логика

\section{История статьи:}

Статья поступила 27.11.2019

Статья принята к публикации 09.01.2020

Для цитирования: «Длящиеся слова», треугольник Пирса и тетраэдр онтологической Прописи// Вестник Российского университета дружбы народов. Серия: Философия. 2020. T. 24. No 2. C. 244-261. DOI: 10.22363/2313-2302-2020-24-2-244-261

\section{Сведения об авторе:}

Павленко А.Н. - доктор философских наук, профессор, ведущий научный сотрудник Института философии PAH (e-mail: anpavlenko@mail.ru). 